\title{
Penggunaan Aplikasi Ubidots untuk Sistem Kontrol dan Monitoring pada Gudang Gula Berbasis Arduino UNO
}

\author{
Agung Tri Putra ${ }^{1}$, Risfendra ${ }^{2}$ \\ 1,2Universitas Negeri Padang \\ Jl. Prof Dr. Hamka Air Tawar, Padang, Indonesia \\ agungtp08@gmail.com ${ }^{1}$,risfendra@ft.unp.ac.id ${ }^{2}$
}

\begin{abstract}
Sugar is a food staple which is very important for daily life both in households and industries. Many industries experience problems during the sugar storage process because of the difficulty in controlling and monitoring temperature and humidity in their storage warehouse. By using the Ubidots application as a tool for controlling and monitoring which can be operated simultaneously. This application is a platform that makes it easier for users to retrieve data from the DHT22 sensor and convert it into information. To assist users in collecting data in one storage, Ubidots also provides an API (Application Programming Interface) to make changes and retrieve data from the web server. The process of sending data to applications and web servers operated online, in other words, requires an internet network. Sending and receiving of this data uses NodeMCU as a wi-fi interface on this system. In the end, the Ubidots application can control the opening and closing of the gate and monitoring the humidity temperature of the application in real time as well as retrieving data using API on the web server so that good quality sugar is obtained
\end{abstract}

Keywords - Warehouse, Ubidots, DHT22, Web Server, NodeMCU

Abstrak - Gula merupakan bahan pokok pangan yang sangat penting bagi kehidupan sehari-hari baik dalam rumah tangga maupun industri. Banyak industri yang mengalami masalah pada saat proses penyimpanan gula karena sulit nya mengontrol dan memonitoring suhu serta kelembaban pada gudang penyimpanannya. Dengan menggunakan aplikasi Ubidots sebagai alat untuk mengontrol dan memonitoring yang bisa dioperasikan secara bersamaan. Aplikasi ini merupakan platform yang mempermudah user dalam pengambilan data dari sensor DHT22 dan mengubahnya menjadi informasi. Untuk membantu user dalam pengumpulan data disatu penyimpanan, Ubidots juga menyediakan API (Application Programming Interface) untuk melakukan perubahan dan pengambilan data dari web server. Proses pengiriman data ke aplikasi dan web server dioperasikan secara online dengan kata lain memerlukan jaringan internet. Pengiriman dan penerimaan data ini menggunakan NodeMCU sebagai mpdul wi-fi pada sistem ini. Dalam hasil akhirnya aplikasi Ubidots dapat melakukan pengontrolan buka tutup gerbang dan monitoring suhu kelembaban dari aplikasi secara real time maupun pembambilan data kembali menggunakan API pada web server sehingga didapatkan gula dengan kualitas yang baik.

Kata kunci- Gudang, Ubidots, DHT22, Web Server, NodeMCU

\section{Pendahuluan}

Gula menjadi bahan pokok pangan dan sangat penting bagi kehidupan sehari-hari, Gula sangat dibutuhkan bagi tubuh manusia karena mengandung kalori sebagai sumber energi untuk beraktifitas sehari-hari dan gula juga digunakan sebagai penyusun utama bahan pemanis oleh industri makanan dan minuman. Berdasarkan sebuah penelitian scanning electron micrograph (SEM) mengatakan bahwa suhu dan kelembaban suatu ruangan dapat mempengaruhi kualitas gula sehingga penggumpalan dapat terjadi dalam proses penyimpanannya. Kondisi ideal ruangan untuk penyimpanan gula bisa didapatkan dengan suhu ruangan $30^{\circ} \mathrm{C}$ dan kelembaban $67,89 \%$ [1].

Dengan memanfaatkan konsep Internet of Thing (IoT) dapat dilakukan pengontrolan dan monitoring gudang gula lebih efektif, maka dari itu Tugas Akhir ini mengkombinasikan antara sistem IoT dengan sistem monitoring secara real time menggunakan aplikasi Ubidots dan web server yang dapat diakses dimana saja asalkan terkoneksi dengan jaringan internet.

Sistem kerja alat ini adalah ketika suhu tidak mencapai set point yang di tentukan, maka lampu akan hidup secara otomatis sampai kondisi suhu ruangan mencapai set point, dan apabila suhu melebihi set point maka kipas DC otomatis hidup untuk menurunkan suhu ruangan sehingga suhu ruangan warehouse tetap terjaga dan ideal.

\section{Gudang Penyimpanan (Warehouse)}

Gudang adalah suatu bangunan atau ruangan yang berfungsi sebagai tempat penyimpanan seluruh barang ataupun bahan-bahan dari sebuah perusahaan[2]. Dalam skala yang lebih kecil pemanfaatan ruangan bisa dijadikan tempat penyimpanan/gudang. Tetapi berbeda jika barang yang diproduksi dalam jumlah besar dan sudah memiliki perusahaan. Gudang salah satu aspek penting yang harus 
dimiliki dalam sebuah perusahaan karena disana terjadi proses pengolahan input menjadi output. Proses yang terjadi dalam gudang meliputi produksi bahan mentah, barang setengah jadi dan barang jadi yang sudah siap untuk di pasarkan.

\section{Arduino UNO}

Arduino UNO merupakan sebuah board mikrokontroler yang bersifat open source. Arduino UNO berbasis chip ATmega328 dengan paket kemasan Dual Inline Package (DIP). Untuk menggunakan komunikasi serial atau sebagai uploader USB, Arduino UNO memiliki chip mikrokontroler ATmega16U2[3].

\section{Sensor DHT22}

Sensor DHT22 adalah tipe sensor suhu yang bisa mengukur kelembaban sekaligus. DHT22 mampu mengukur suhu dari $-40^{\circ} \mathrm{C}-125^{\circ} \mathrm{C}$ dan kelembaban udara 0\%-100\%. Sensor ini memiliki tingkat akurasi pengukuran masing-masing nya dibawah $2 \%$, hal ini membuat DHT22 bisa dijadikan acuan komponen utama dalam melakukan pengukuran suhu dan kelembaban [4].

\section{Sensor Passive InfraRed (PIR)}

Sensor PIR adalah sensor yang mempunyai prinsip kerja berdasarkan sinyal inframerah. Sensor PIR ini berbeda dengan sensor inframerah lainnya yaitu pada sensor ini hanya menangkap pancaran sinyal inframerah dari tubuh manusia sedangkan sensor lainnya bekerja secara aktif atau menembakan sinyal inframerah pada objek. PIR dapat bekerja pada tagangan 5 VDC lebih dari itu akan dapat merusak PIR itu sendiri. Jarak yang dapat didetksi oleh PIR sejauh 5 meter dari posisi PIR berada[5].

\section{Motor DC}

Motor DC adalah motor listrik yang bekerja pada saat dialiri listri arus searah. Seperti motor listrik pada umumnya motor DC merubah energi listrik menjadi energi mekanik, dimana energi mekanik yang dihasilkan dari medan magnet yang terbentuk dari rotor sebagai bagian yang berputar sedangkan stator bagian kumparan yang tidak berputar[6].

\section{Liquid Crystal Display (LCD)}

Liquid Cristal Display (LCD) merupakan jenis komponen elektronika yang unik karena dapat menampilkan berbagai informasi yang diinginkan berupa angka, huruf dan karakter. LCD terdiri dari seven segment dan elektroda, prinsip kerja dari LCD yaitu ketika elektroda diberi tegangan maka molekul-molekul pembentuk komponen ini akan menyesuaikan diri dengan elektroda dan seven segment [7].

\section{Kipas DC}

Kipas DC menggunakan kumparan kawat tembaga untuk mengubah energi listrik menjadi gerakan balingbaling sehingga bisa menghembuskan angin[8]. Saat aliran listrik bertegangan DC diberikan ke kabel kipas, maka arus listrik yang masuk ke kipas akan langsung dirubah menjadi medan magnet dan membuat kipas langsung berputar. Arah putaran kipas tersebut sesuai dengan arah aliran listrik yang diberikan

\section{Real Time Clock DS3231 [RTC3231]}

RTC adalah IC yang memiliki fungsi sebagai pewaktuan digital. RTC mampu menghitung waktu mulai dari tahun pada saat itu hingga menghitung detik secara berkala. Jam yang terdapat pada RTC dioperasikan dalam hitungan 12 jam atau 24 jam yang memudahkan pengguna untuk mendapatkan informasi waktu yang dibutuhkan[9].

\section{NodeMCU (ESP8266)}

NodeMCU adalah board elektronika yang mempunyai fungsi hamper sama dengan Arduino UNO, yang membedakan NodeMCU dengan Arduino UNO yaitu chip yang digunakan serta NodeMCU dapat berkomunikasi dengan jaringan internet. NodeMCU salah satu solusi dalam pembuatan ataupun perancangan sebuah proyek IoT (Internet of Thing). NodeMCU terdiri dari beberapa tipe dan pada NodeMCU ESP8266 merupakan NodeMCU yang berbasis ESP8266 dan termasuk tipe ESP-12 [10].

\section{Ubidots}

Ubidots adalah sebuah aplikasi yang mampu menjalankan konsep IoT. Aplikasi ini dikembangkan di Boston, Amerika Serikat, dengan tujuan dapat melakukan pengambilan data dari berbagai input dan juga bisa mengatur sebuah aksi pada output yang diinginkan [11].

Ubidots juga dilengkapi sebuah fitur yang dapat menyimpan data pada database sehingga memungkin user mendapatkan data terdahulu sebagai pembanding untuk data yang baru saja didapatkan. API (Application Programming Interface) merupakan fitur yang dimiliki oleh Ubidots tersebut. Untuk menjalankan API user harus mendapatkan API key terdahulu. Cara mendapatkan API key ini bersamaan dengan proses mendapatkan kode token untuk menggunakan Ubidots, jadi sewaktu proses sign up pihak Ubidots akan memberikan kedua kode tersebut.

Relay

Relay adalah saklar elektrik yang menggunakan elektromagnet untuk memindahkan saklar dari posisi off ke posisi on melalui trigger yang sudah diberikan. Relay pada dasarnya dibagi atas 2 macam yaitu NC (Normally Close) dan NO (Normally Open).

\section{Metode}

Pada bab ini akan membahas tentang perancangan hardware dan software.

\section{Blok Diagram}

Blok diagram merupakan pendefinisian terhadap sistem yang dirancang bersifat menyeluruh bias dilihat pada Gambar 1.

\section{Arduino UNO}

Arduino UNO berfungsi sebagai otak atau pusat pengolahan data dari input berupa sensor, ESP8266, limit switch, dan RTC DS3231 menuju output seperti Lampu, kipas DC, motor DC, serta monitoring LCD dan Ubidots.

\section{Sensor DHT22}

Sensor DHT22 berfungsi untuk pembacaan terhadap suhu dan kelembaban yang pada gudang gula. Hal ini 
dilakukan untuk menjaga suhu dan kelembaban pada warehouse agar tetap berada pada set point yang ditentukan.

\section{Sensor PIR}

Sensor PIR ini berfungsi untuk pembacaan gerakan/ motion pada gerbang gudang jika ada penyusup atau orang yang tidak berkepentingan yang mencoba masuk kedalam maka sensor akan mengubah besaran panas dari suhu tubuh manusia menjadi besaran listrik yang dikirimkan ke Arduino lalu diterima oleh user sebagai notifikasi.

4. ESP8266

ESP8266 adalah modul Wi-Fi yang berfungsi sebagai sistem jaringan internet yang mengirimkan data yang sudah diolah oleh Arduino UNO ke user sehingga dapat mengetahui data dari pengukuran sensor.

5. Ubidots

Ubidots merupakan sebuah aplikasi pada android yang berfungsi sebagai monitoring gudang yang servernya terlebih dahulu didaftarkan melalui web agar bisa mendapatkan kode token tersendiri .

\section{RTC DS3231}

RTC DS3231 berfungsi untuk memberikan data secara real time seperti tahun, bulan, tanggal, hari, jam, menit, dan detik secara akurat sehingga bisa mendapatkan informasi secara langsung.

\section{Relay}

Relay digunakan untuk menghidupkan dan mematikan lampu yang akan bekerja jika sudah diberikan sinyal listrik oleh Arduino UNO.

\section{Lampu}

Lampu berfungsi sebagai proteksi pertama yang menjaga suhu dan kelembaban pada ruangan warehouse tetap pada set point.

9. Kipas DC

Kipas DC berfungsi sebagai proteksi kedua apabila suhu melebihi batas atas dari set point maka kipas dc otomatis akan hidup dan menurunkan suhu ruangan hingga mencapai set point yang ditentukan.

\section{LCD}

LCD berfungsi sebagai interface yang ditampilkan pada alat agar dapat mengetahui berapa suhu dan kelembaban pada gudang gula.

11.Motor DC $12 \mathrm{~V}$ diletakan pada gerbang yang berfungsi untuk membuka dan menutup gerbang

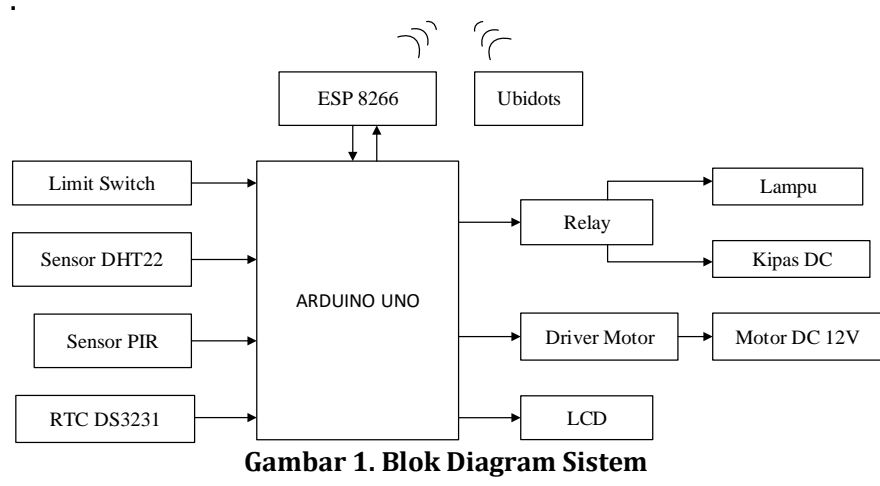

\section{Rangkaian Keseluruhan}

Rangkaian keseluruhan meliputi, pembacaan suhu dan kelembaban, menampilkan data secara real time melalui LCD, pendeteksian gerakan (motion), pengontrolan kipas dan lampu sehingga bisa hidup pada kondisi tertentu dan pengkoneksian modul wi-fi ke Arduino UNO agar keseluruhan sistem dapat di kontrol dan dimonitoring lewat android menggunakan jaringan internet. Rangkaian keseluruhan dapat dilihat pada Gambar 2.

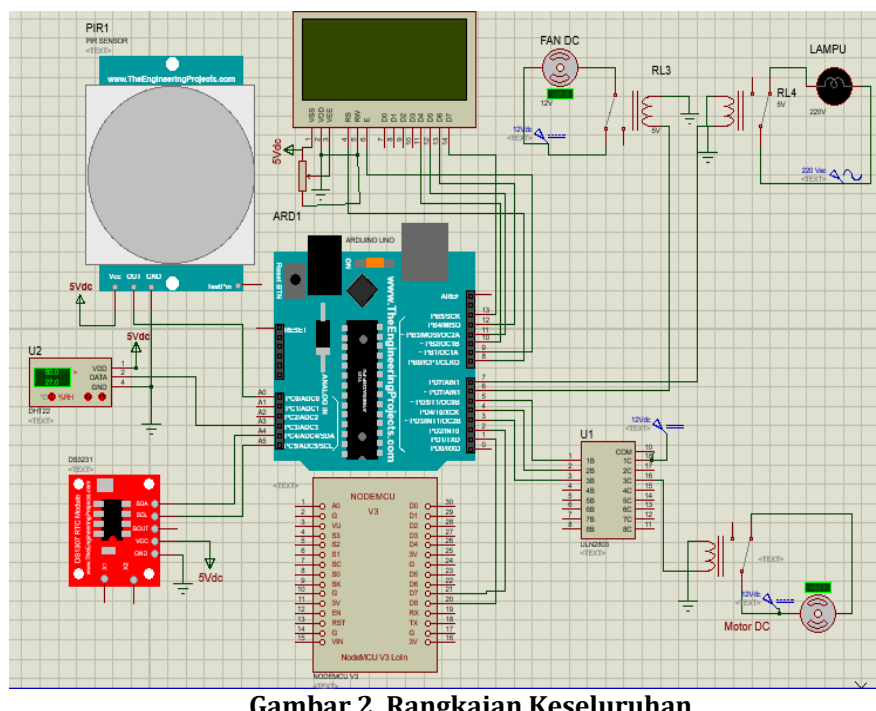

Gambar 2. Rangkaian Keseluruhan

\section{Perancangan Hardware}

Perancangan Hardware berfungsi untuk mengetahui komponen yang digunakan serta bentuk mekanik Tugas Akhir yang ingin dibuat. Secara tidak langsung perancangan Hardware sangat penting untuk menjadi langkah awal dalam proses pembuatan Tugas akhir.

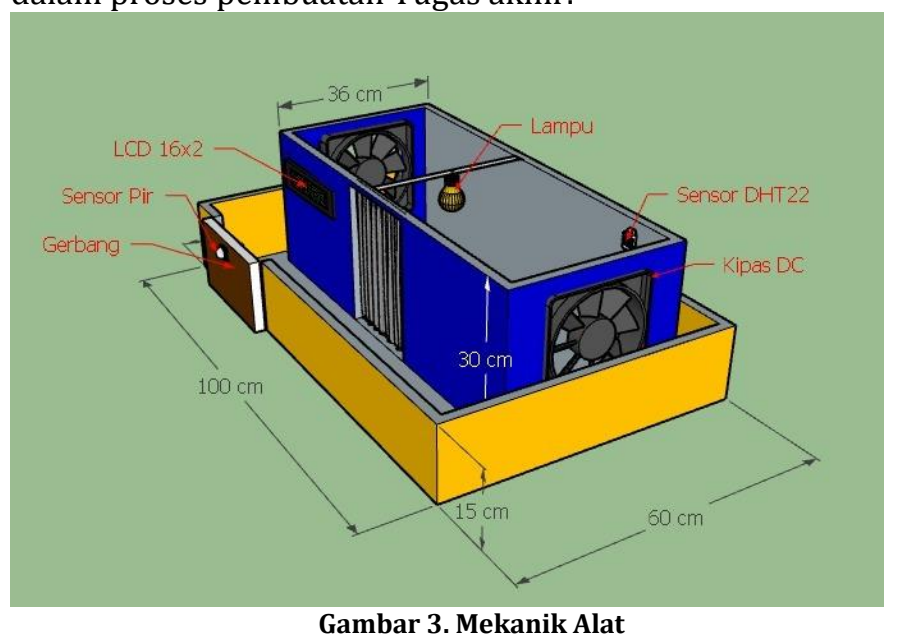

Pada Gambar 3. merupakan perancangan mekanik alat yang dibuat dengan menggunakan akrilik serta atap asbes dan tirai pada pintu masuk. 


\section{Prinsip Kerja Alat}

Prinsip kerja alat ini adalah sebagai sistem kontrol dan monitoring pada gudang penyimpanan gula agar bisa mengontrol suhu dan kelembaban ruangan secara otomatis dan memonitor suhu dan kelembaban secara real time melalui android menggunakan aplikasi Ubidots.

Pada prinsipnya sistem kontrol bekerja saat inisialisasi sensor DHT22. Pada saat suhu berada pada batas bawah $<29^{\circ} \mathrm{C}$ maka lampu otomatis hidup dan membuat suhu ruangan naik hingga mencapai set point yang ditentukan yaitu $\geqslant 29^{\circ} \mathrm{C}$ dan jika suhu berada pada batas atas $>31^{\circ} \mathrm{C}$ kipas DC otomatis akan menyala membuat suhu ruangan turun hingga mencapai set point yang ditentukan yaitu $\leqslant 31^{\circ} \mathrm{C}$ ini bertujuan agar suhu dan kelembaban gudang gula tetap ideal dan kualitas gula tetap terjaga.

Pada sistem monitoring mempunyai 2 buah objek yang diamati, yang pertama yaitu mendeteksi keberadaan manusia pada pintu masuk. Alat ini memakai sensor Passive InfraRed (PIR) yang dipasang pada gerbang pintu masuk. Sistem ini dapat mendeteksi adanya manusia melalui suhu tubuh, jadi sewaktu ada orang yang terdeteksi di depan gerbang maka sensor akan mengirimkan data ke arduino diolah dan setelah itu dikirimkan ke android user melalui jaringan internet menggunakan NodeMCU dan otomatis akan keluar pemberitahuan berupa email dan indikator deteksi orang pada Ubidots akan berubah warna. Ini berguna sebagai tindakan antisipasi adanya orang yang tidak berkepentingan yang ingin memasuki gudang dengan kata lain gudang hanya bisa dimasuki oleh user yang memiliki android.

Objek kedua yang diamati yaitu, gula yang prinsip kerjanya pada saat inisialisasi sensor telah selesai maka data akan dikirimkan ke Arduino setelah diolah secara real time hasil pengukuran sensor akan keluar pada aplikasi Ubidots dan tersimpan pada web server nya. Dari hasil tersebut dapat diketahu berapa suhu dan kelembaban pada gudang gula serta hasil pengukuran dapat tersimpan otomatis sehingga user dapat melihat history pengukuran sebelum - sebelumnya.

\section{Perancangan Software}

Pada tugas akhir ini menggunakan aplikasi Ubidots sebagai monitoring untuk pengukuran suhu dan kelembaban serta notifikasi untuk mengetahui keberadaan orang di depan gerbang. Jadi pada saat alat atau system dijalankan hasil pengukuran pada DHT 22 akan dikirimkan ke aplikasi menggunakan NodeMCU dengan jaringan internet lalu memberikan notifkasi jika terdeteksi keberadaan manusia didepan pintu gerbang.

Tampilan pada aplikasi Ubidots ini meliputi, tampilan suhu dan kelembaban secara real time, tombol button untuk membuka pintu gerbang serta indikator deteksi orang. Pada Gambar 4. merupakan tampilan setelah aplikasi Ubidots diinstal pada android.

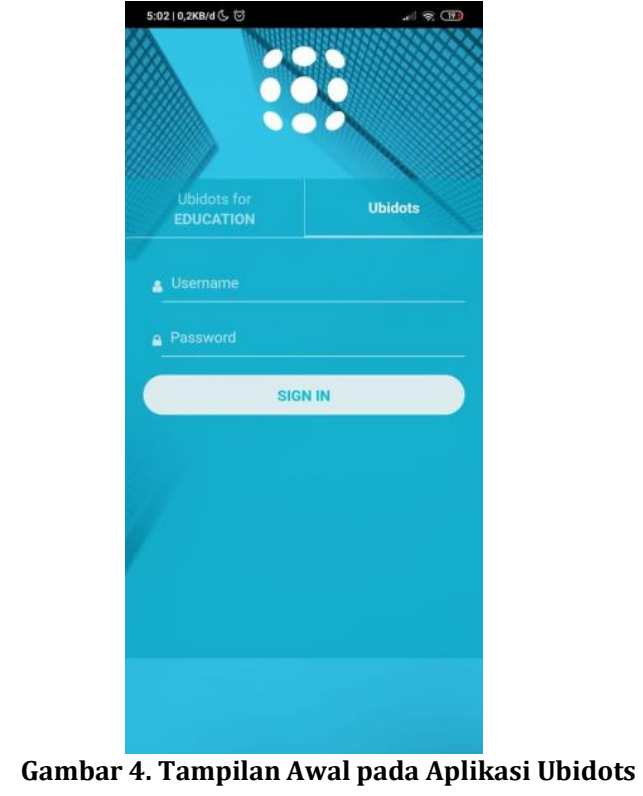

\section{Diagram Alir (Flowchart)}

Pada tugas akhir ini di terdapat 2 buah flowchart untuk menjelaskan bagaimana keseluruhan sistem dan pendeteksian gerakan menggunakan sensor PIR bekerja. Berikut ini flowchart sistem pendeteksian gerakan (motion) pada Gambar 5 dan flowchart keseluruhan sistem dalam gudang pada Gambar 6

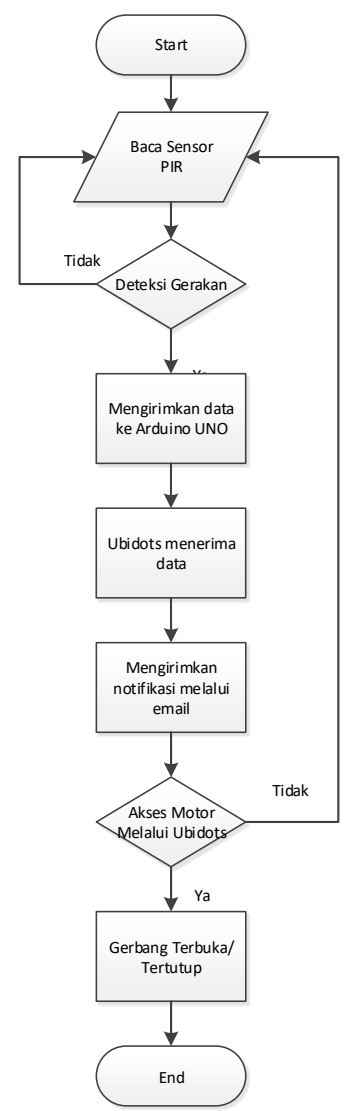

Gambar 5. Flowchart Sistem Pendeteksian Gerakan 
Berikut penjelasan untuk flowchart pada Gambar 5. :

1. Mulai.

2. Sensor PIR telah aktif.

3. Pendeteksian gerakan oleh PIR berdasarkan sinar infra merah yang dipancarkan dari suhu tubuh manusia.

4. Mengirimkan hasil data dari PIR ke Arduino UNO dan diolah lalu meneruskan ke Ubidots.

5. Ubidots menerima hasil pendeteksian gerakan apakah terdeteksi atau tidak.

6. Ubidots mengirimkan notifikasi ke user melalui email.

7. Mendeteksi apakah yang ingin mencoba memasuki gudang ini penyusup atau tidak, jika tidak user bisa langsung menuju ke proses buka gerbang melalui Ubidots.

8. Selesai.

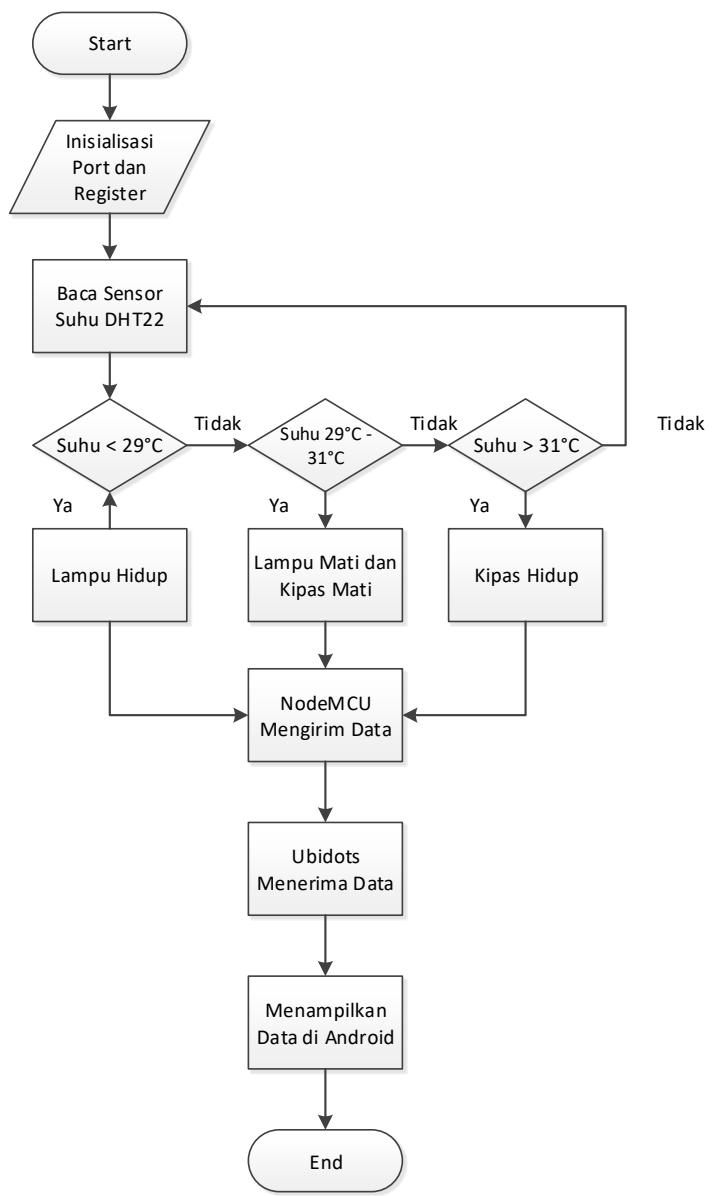

Gambar 6. Flowchart Keseluruhan Sistem dalam Gudang

Berikut penjelasan untuk flowchart pada Gambar 6. :

1. Mulai.

2. Inisialisasi register dan port oleh Arduino UNO.

3. DHT22 melakukan pengukuran suhu dan kelembaban pada gudang. Jika suhu kecil dari $29^{\circ} \mathrm{C}$ maka lampu akan hidup dan apabila suhu besar dari $31^{\circ} \mathrm{C}$ kipas DC akan hidup, sedangkan saat rentang suhu pada $29^{\circ} \mathrm{C}-31^{\circ} \mathrm{C}$ kondisi suhu ruangan gudang dalam keadaan ideal.

4. NodeMCU mengirim seluruh data hasil pengukuran dari DHT22 dengan menggunakan koneksi internet.
Sebelumnya NodeMCU harus dikoneksikan terlebih dahulu dengan cara mensetting username dan password pada mobile hotspot atau Wi-Fi yang akan digunakan. Username dan password ini harus sama penulisan nya dengan program yang sudah diatur pada Arduino IDE.

5. Hasil data pengukuran diterima oleh Ubidots.

6. Ubidots menampilkan data pada android user.

7. Selesai.

\section{HASIL DAN PEMBAHASAN}

Pada pembuatan Tugas Akhir ini dibangun dengan menggunakan beberapa komponen yang sudah di hubungkan satu sama lainnya dan berpusat pada Arduino UNO.

\section{Pengujian Mekanik Alat}

Pengujian mekanik bertujuan untuk membandingkan hasil pada perancangan dengan hasil pembuatan. Pada perancangan Tugas Akhir ini dibuat dalam bentuk prototype dengan menyerupai bentuk aslinya yang terdapat dilapangan. Pada hasil pembuatan alat penggunaan akrilik sebagai konstruksi utama sudah terealisasi. Bentuk alat terdapat pada Gambar 7.

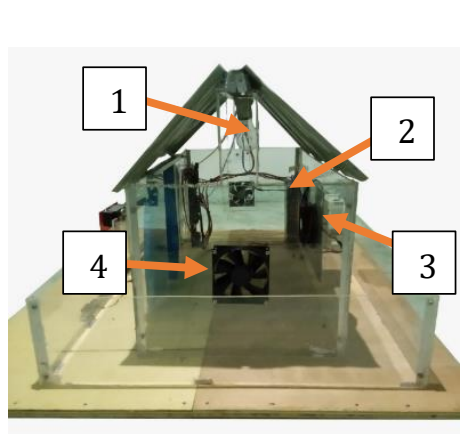

(a)

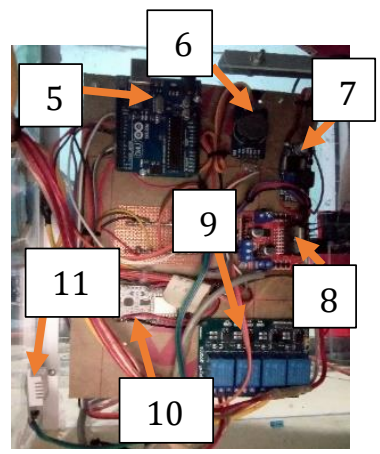

(b)

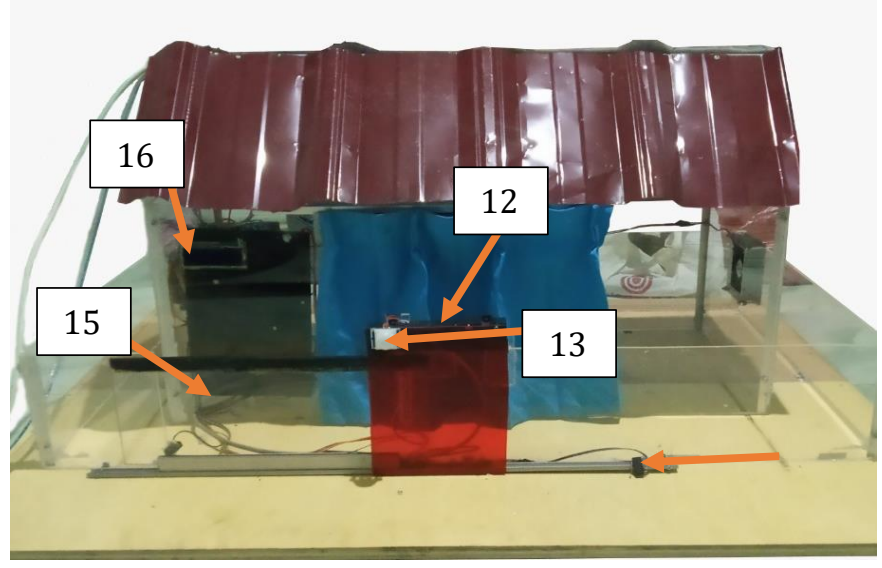

(c)

Gambar 7. (a) Mekanik Alat Tampak Samping, (b) Rangkaian Elektronik (c), Mekanik Alat Tampak Depan

Berikut adalah bagian-bagian komponen yang terdapat pada mekanik alat berdasarkan Gambar 7. : 
1. Lampu $220 \mathrm{VAC}$

2. Power Supply 12 VDC

3. Peltier

4. Kipas

5. Arduino Uno

6. Real Time Clock (RTC)

7. DC to DC Konverter

8. Driver Motor

9. Relay 4 Channel

10. NodeMCU ESP8266

11. Sensor DHT22

12. Motor DC

13. Sensor PIR

14. Limit Switch

15. Gerbang Warehouse

16. Liquid Crystal Display (LCD)

\section{Pengujian Suhu dengan Sensor DHT22}

Hasil pengujian suhu pada Sensor DHT 22 dengan perbandingan thermometer yang terdapat pada Tabel 1.

Tabel 1. Hasil Pengukuran Suhu dengan Sensor DHT22

\begin{tabular}{|l|c|c|c|c|c|}
\hline \multirow{2}{*}{ No. } & Waktu & \multicolumn{2}{|c|}{ Hasil Pengujian } & Selisih & Error \\
\cline { 3 - 4 } & (Menit) & DHT22 & Thermometer & Error & $(\%)$ \\
\hline 1. & 1 & $23.5^{\circ} \mathrm{C}$ & $24.3^{\circ} \mathrm{C}$ & 0.8 & 3.2 \\
\hline 2. & 5 & $28.5^{\circ} \mathrm{C}$ & $29.3^{\circ} \mathrm{C}$ & 0.8 & 2.7 \\
\hline 3. & 9 & $32.2^{\circ} \mathrm{C}$ & $33.1^{\circ} \mathrm{C}$ & 0.8 & 2.7 \\
\hline 4. & 13 & $36.6^{\circ} \mathrm{C}$ & $37.2^{\circ} \mathrm{C}$ & 0.6 & 1.6 \\
\hline 5. & 17 & $40.1^{\circ} \mathrm{C}$ & $40.4^{\circ} \mathrm{C}$ & 0.3 & 0.7 \\
\hline \multicolumn{7}{|c|}{ Rata - Rata Error (\%) } & 2.18 \\
\hline
\end{tabular}

Berdasarkan data pada Tabel 1. terlihat selisih pada saat pengukuran suhu antara DHT22 dengan thermometer lebih kecil pada saat suhu terus mengalami kenaikan. Adapun rumus dari perhitungan nilai presentase error dan rata-rata error dari pengukuran suhu menggunakan DHT22 sebagai berikut :

$$
\text { Persentase Error }(\%)=\frac{\text { Nilai Sensor }- \text { Nilai Acuan }}{\text { Nilai Acuan }} \times 100 \%
$$

Nilai sensor didapatkan melalui DHT22 yang terukur sedangkan nilai acuan berdasarkan thermometer yang terukur. Dari hasil persentase error pada suhu dapat dikatakan DHT22 mampu beroperasi dengan baik.

\section{Pengujian Kelembaban dengan Sensor DHT22}

Hasil pengujian kelembaban pada Sensor DHT 22 dengan perbandingan thermometer yang terdapat pada Tabel 2.

Tabel 2. Hasil Pengukuran Kelembaban dengan Sensor DHT22

\begin{tabular}{|c|c|c|c|c|c|}
\hline \multirow{2}{*}{ No. } & \multirow{2}{*}{$\begin{array}{l}\text { Waktu } \\
\text { (Menit) }\end{array}$} & \multicolumn{2}{|c|}{ Hasil Pengujian } & \multirow{2}{*}{$\begin{array}{l}\text { Selisih } \\
\text { Error }\end{array}$} & \multirow{2}{*}{$\begin{array}{l}\text { Error } \\
(\%)\end{array}$} \\
\hline & & DHT22 & Thermometer & & \\
\hline 1. & 1 & $89.2 \%$ & $83.5 \%$ & 5.7 & 6.8 \\
\hline 2. & 5 & $78.2 \%$ & $73.9 \%$ & 4.3 & 5.8 \\
\hline 3. & 9 & $71.7 \%$ & $68.9 \%$ & 2.8 & 4 \\
\hline 4. & 13 & $54.8 \%$ & $53.5 \%$ & 1.3 & 2.4 \\
\hline 5. & 17 & $43.9 \%$ & $43.4 \%$ & 0.5 & 1.1 \\
\hline \multicolumn{5}{|c|}{ Rata - Rata Error (\%) } & 4.02 \\
\hline
\end{tabular}

Berdasarkan data pada Tabel 2. terlihat selisih pada saat pengukuran kelembaban antara DHT22 dengan thermometer lebih kecil pada saat suhu terus mengalami kenaikan. Adapun rumus dari perhitungan nilai presentase error dan rata-rata error dari pengukuran kelembaban menggunakan DHT22 sebagai berikut:

$$
\text { Persentase Error (\%) }=\frac{\text { Nilai Sensor }- \text { Nilai Acuan }}{\text { Nilai Acuan }} \times 100 \%
$$

Sama halnya dengan dengan pengujian suhu, pada pengujian ini nilai sensor diambil dari DHT22 yang terukur dan nilai acuan berdasarkan thermometer yang terukur. Dari hasil persentase error kelembaban memiliki error yang lebih besar dibandingkan error dalam pengukuran suhu.

\section{Pengujian LCD}

Pengujian LCD dilakukan sebagai upaya pengecekan kondisi apakah LCD layak atau tidak digunakan. Jika LCD tidak menampilkan data berupa suhu, kelembaban dan jam pada saat itu maka bisa dikatakan LCD tidak layak untuk digunakan dalam proses pembuatan Tugas Akhir ini.

Cara mengetahui suhu dan kelembaban pada alat secara real time selain menggunakan Ubidots yaitu dengan menggunakan LCD $2 \times 16$. LCD merupakan output yang bisa menampilkan tulisan sehingga dapat membuat user lebih mengerti terhadap hasil pengukuran yang didapat. Tampilan LCD pada saat menampilkan hasil pengukuran dapat dilihat pada Gambar 8. 


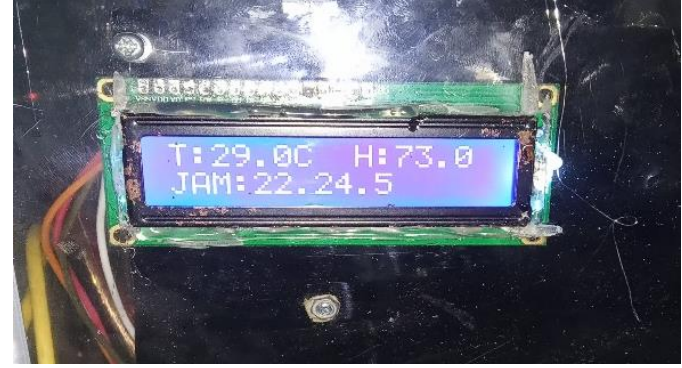

Gambar 8. Tampilan Suhu dan Kelembaban

\section{Pengujian Jarak pada Sensor PIR}

Sensor PIR memiliki kemampuan terbatas dalam pembacaan gerakan (motion), ini tergantung dengan kualitas sensor PIR yang dimiliki.

Tabel 3. Pendeteksian Jarak pada PIR

\begin{tabular}{|l|c|c|c|l|}
\hline No. & Jarak & Tegangan & Logika & Keterangan \\
\hline 1. & $20 \mathrm{~cm}$ & 4.7 VDC & 1 & Terdeteksi \\
\hline 2. & $40 \mathrm{~cm}$ & 4.7 VDC & 1 & Terdeteksi \\
\hline 3. & $60 \mathrm{~cm}$ & 4.7 VDC & 1 & Terdeteksi \\
\hline 4. & $80 \mathrm{~cm}$ & 4.7 VDC & 1 & Terdeteksi \\
\hline 5. & $1 \mathrm{~m}$ & 4.7 VDC & 1 & Terdeteksi \\
\hline 6. & $1.2 \mathrm{~m}$ & 4.7 VDC & 0 & Tidak \\
& & & & Terdeteksi \\
\hline
\end{tabular}

Berdasarkan data pengujian pada Tabel 3. maka dapat diketahui bahwa batas dari pembacaan sensor PIR pada jarak 1 meter dan apabila objek melebihi jarak tersebut sensor PIR tidak dapat membaca pergerakan atau objek di depan gerbang. Tegangan yang terukur pada saat sensor membaca pergerakan yaitu 4.7 Volt dan ini berlaku saat sensor pir sudah di aliri oleh tegangan yang diberikan. Logika biner yang berlaku dalam pembacaan gerakan oleh sensor pir adalah 1 dan 0 yang memiliki arti 1 pada saat sensor mendeteksi pergerakan dan 0 pada saat sensor tidak mendeteksi pergerakan.

\section{Pengujian Pengontrolan Suhu pada Gudang}

Tujuan pengujian ini adalah untuk memastikan bahwa sistem yang sudah dibuat berjalan sesuai dengan yang diinginkan dan tidak terjadi kesalahan pada saat menaikan atau menurunkan suhu pada alat. Penulis mengambil sample suhu 4 derajat diatas set point dan 4 derajat dibawah set point. Hasil pengujiannya dapat dilihat Tabel 4 .
Tabel 4. Hasil Pengujian Pengontrolan Suhu

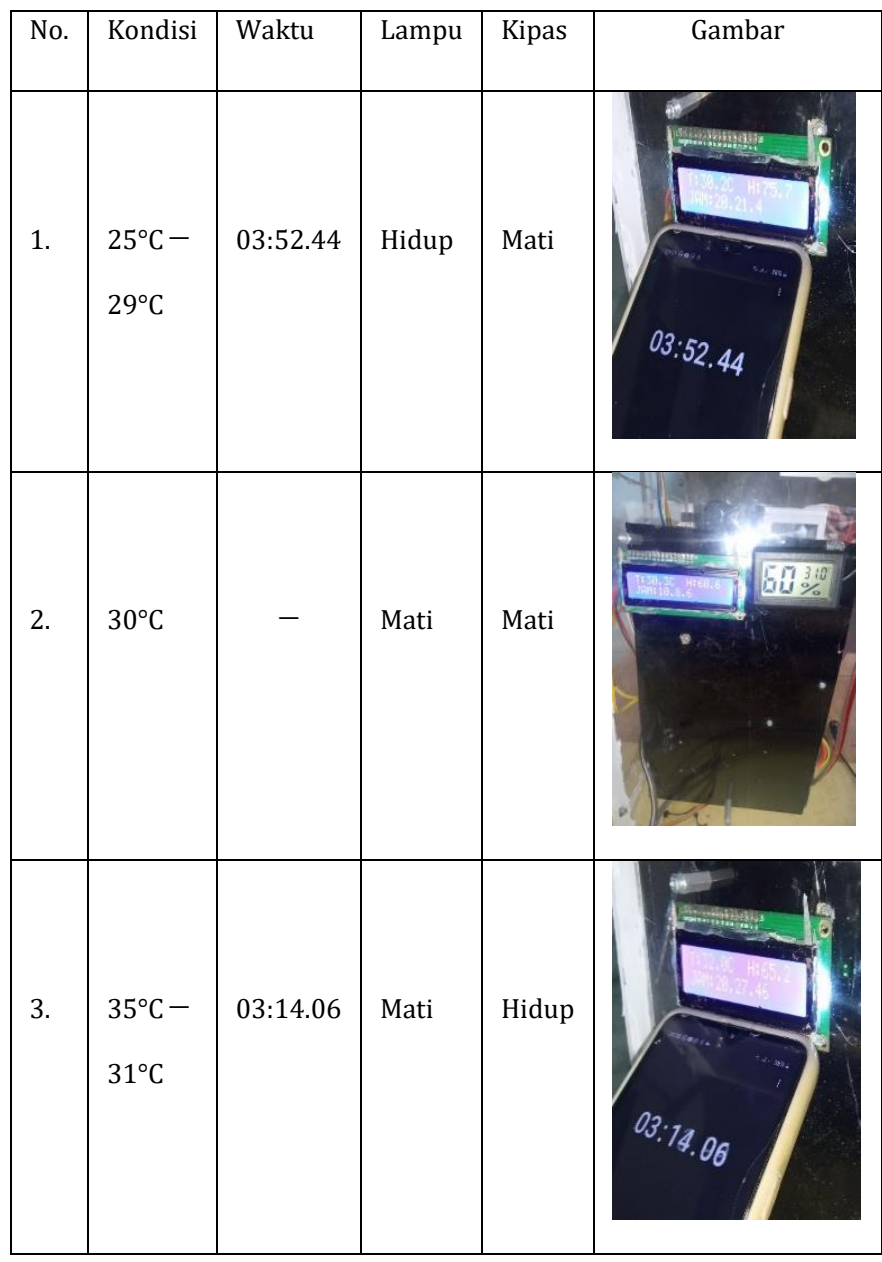

Dapat dilihat dari tabel diatas sistem pengontrolan suhu mempunyai 3 buah kondisi. Pada tabel pengujian nomor 1 adalah ketika pengukuran sensor DHT22 sudah menunjukan batas bawah nya yang bernilai $<29^{\circ} \mathrm{C}$. Disini alat diatur agar bisa menaikan suhu dari 25 derajat Celcius. Proses menaikan suhu ruangan pada alat menggunakan lampu dengan daya yang lumayan besar sehingga suhu ruangan cepat mencapai suhu ideal yang sudah ditentukan.

Tabel nomor 2 adalah kondisi dimana saat alat tidak bekerja dikarenakan sudah mencapai suhu ideal yang ditentukan dengan rentang nilai $29^{\circ} \mathrm{C}-31^{\circ} \mathrm{C}$. Lamanya waktu pada saat kondisi ideal ini tergantung dengan suhu ruangan dimana gudang tersebut diuji. Karena suhu ruangan tiap daerah berbeda - beda.

Dan kondisi yang terakhir yaitu pada saat pengkururan suhu menunjukan angka $>31^{\circ} \mathrm{C}$ yang merupakan batas atas dari yang ditentukan. Disini alat juga diatur agar bisa menurunkan suhu dari 35 derajat Celcius. Maka dengan Kipas beserta Peltier mampu menurunkan suhu ruangan sehingga mencapai suhu idealnya. 


\section{Pengujian Aplikasi Ubidots}

Pengujian aplikasi Ubidots yaitu menguji alat dengan cara memonitoring dan melakukan kontrol gerbang melalui aplikasi Ubidots. Dimana user bisa mengakses data secara online dengan menggunakan android dan web server. Selama sistem masih terhubung dengan jaringan internet monitoring secara real time masih dapat dilakukan.

Pada aplikasi Ubidots akan memonitoring suhu dan kelembaban serta merekam data pada web server sehingga user dapat melihat history pengukuran. Pendeteksian orang di depan gerbang dan membuka/menutup gerbang juga dilakukan pada aplikasi Ubidots. Tampilan monitoring pada aplikasi Ubidots dapat dilihat pada Gambar 9.

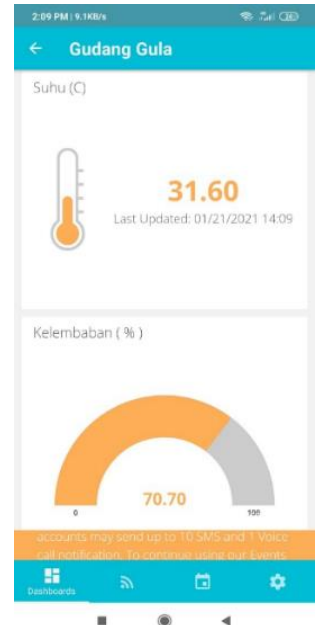

(a)

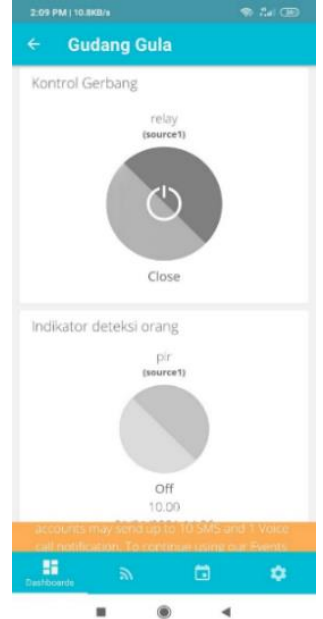

(b)
Gambar 9. (a) Tampilan Suhu dan Kelembaban, (b) Kontrol Gerbang dan Indikator Deteksi Pergerakan

Pada Gambar 9. terbagi menjadi 2 potongan gambar, potongan gambar (a) merupakan tampilan suhu dan kelembaban gudang secara real time. Data suhu dan kelembaban pada Ubidots akan diupdate setiap 1 menit sekali. Gambar (b) berisikan button buka gerbang dan indikator pendeteksian gerakan. Pada saat button di sentuh otomatis gerbang pada gudang akan terbuka/tertutup, indikator deteksi gerakan akan berubah warna menjadi hijau apabila mendeteksi suatu gerakan di depan gerbang.

Berikut tampilan history data suhu dan kelembaban yang berada pada web server Ubidots yang dapat dilihat pada Gambar 10. Dan notifikasi ke email pada saat terdeteksi gerakan di depan gerbang pada Gambar 10.

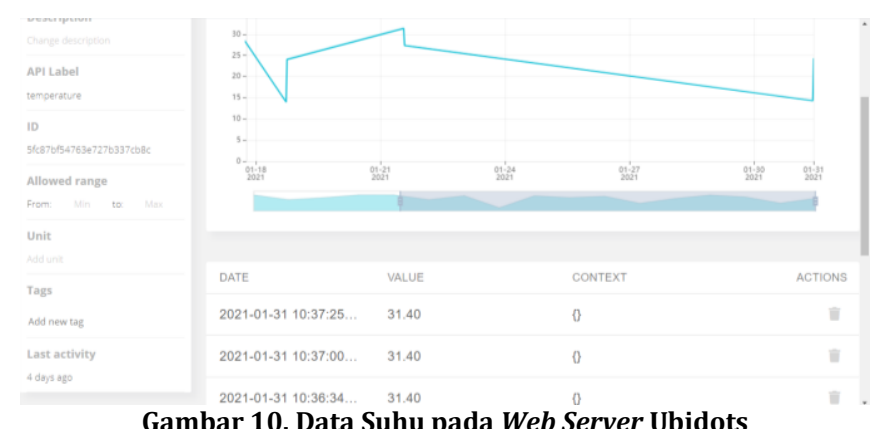

Gambar 10. Data Suhu pada Web Server Ubidots

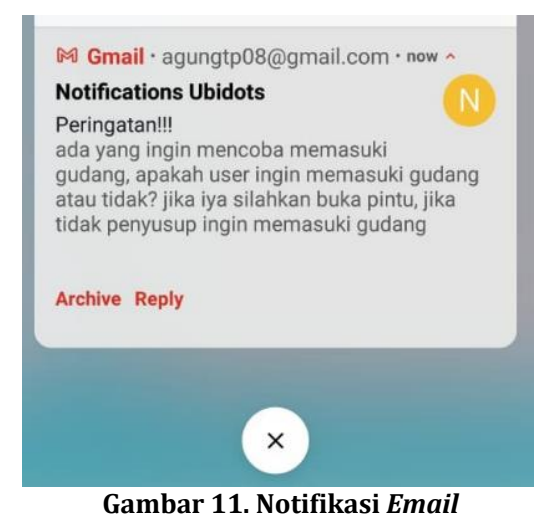

Pada Gambar 10. dapat dilihat bahwa data suhu gudang tersimpan pada web server. Data ini juga dapat didownload secara langsung Grafik yang terdapat pada web server ini berfungsi untuk mempermudah user dalam mengamati data yang ada.

Pada Gambar 11. adalah email yang masuk ke user setelah PIR mendeteksi pergerakan dan Ubidots mengirimkan notifikasi berupa email. Notifikasi pada Ubidots dapat diatur sesuai dengan yang dibutuhkan.

\section{PENUTUP}

Berdasarkan pengujian terhadap pembuatan Tugas Akhir ini Penulis bisa mengambil simpulan bahwa sistem keseluruhan alat telah bekerja sesuai yang diinginkan dan proses monitoring data bisa dilakukan dari jarak jauh. Dengan menggunakan Ubidots monitoring data bisa dilakukan lebih efisien dan juga praktis. Disarankan untuk menggunakan akun premium agar bisa menikmati fiturfitur lain yang ada pada Ubidots.

Pengontrolan suhu dan kelembaban pada gudang telah bekerja dengan baik. Terutama untuk suhu gudang yang bisa dijaga agar tetap ideal yaitu pada suhu $30^{\circ} \mathrm{C}$.

\section{REFERENSI}

[1] P. Chitprasert, J. Chedchant, P. Wanchaitanawong, and N. Poovarodom, "Effects of Grain Size, Reducing Sugar Content, Temperature and Pressure on Caking of Raw Sugar," Kasetsart J. (Nat. Sci.), vol. 40, pp. 141-147, 2006.

[2] S. Alhalimi, "Sistem Pendukung Keputusan Pemilihan Lokasi Gudang Penyimpanan Pabrik Dengan Menggunakan Metode Brown-Gibson (Studi Kasus : PT. Inti Kreasi)," 2013.

[3] S. J. Sokop, D. J. Mamahit, and S. Sompie, "Trainer Periferal Antarmuka Berbasis Mikrokontroler Arduino Uno," J. Tek. Elektro dan Komput., vol. 5, no. 3, pp. 13-23, 2016.

[4] W. Gata and R. Tanjung, "Diterbitkan oleh Ikatan Ahli Informatika Indonesia (IAII) | 134 PROSIDING seminar nasional sisfotek Sistem Informasi dan Teknologi Informasi Kendali Ruang Server Menggunakan Sensor Suhu DHT 22, Gerak Pir 
dengan Notifikasi Email," vol. 3584, pp. 134-142, 2017.

[5] B. Prima, "Perancangan Sistem Keamanan Rumah Menggunakan Sensor Pir (Passive Infra Red) Berbasis Mikrokontroler," J. Teknol. Elektron., vol. 1, pp. 1-11, 2010.

[6] T. W. Wisjhnuadji et al., "Home Security System Dilengkapi Notifikasi Sms Dan."

[7] V. T. Bawotong, D. J. Mamahit, M. Eng, and S. R. U. A. Sompie, "Rancang Bangun Uninterruptible Power Supply Menggunakan Tampilan LCD Berbasis Mikrokontroler," E-journal Tek. Elektro dan Komput., vol. 1, pp. 1-7, 2015.

[8] I. Purnamasari and M. Rezasatria, "Rancang Bangun Pengendali Kipas Angin Berbasis Mikrokontroller Atmega 16 Melalui Aplikasi Android Dengan Bluetooth," Simetris J. Tek. Mesin, Elektro dan Ilmu Komput., vol. 10, no. 1, pp. 147-160, 2019, doi: 10.24176/simet.v10i1.2883.

[9] I. R. W. Slamet, A. Junaidi, "Rancang Bangun Kalender Digital Berbasis Arduino." .

[10] N. Hidayati, L. Dewi, M. F. Rohmah, and S. Zahara, "Prototype Smart Home Dengan Modul NodeMCU ESP8266 Berbasis Internet of Things (IoT)," Tek. Inform. Univ. Islam Majapahit, pp. 1-9, 2018.

[11] D. Kuriando, A. Noertjahyana, and R. Lim, "Pendeteksi Volume Air pada Galon Berbasis Internet of Things dengan Menggunakan Arduino dan Android," J. Petra, vol. d, pp. 2-7, 2017, [Online]. Available:

http://publication.petra.ac.id/index.php/teknikinformatika/article/view/5800.

[12] M. Fajar Wicaksono, "Implementasi Modul Wifi Nodemcu Esp8266 Untuk Smart Home," J. Tek. Komput. Unikom-Komputika, vol. 6, no. 1, pp. 9-14, 2017.

\section{Biodata Penulis}

Agung Tri Putra, menyelesaikan studi DIV Teknik Elektro Industri pada Jurusan Teknik Elektro Fakultas Teknik Universitas Negeri Padang.

Risfendra, S.Pd, M.T, Ph.D, lahir di Riau, 13 Februari 1979. Sarjana Teknik Elektronika di Universitas Negeri Padang, lulus tahun 2004, S2 Teknik Sistem Pengaturan, ITS tahun 2008. S3 Shouten Taiwan University, of science and technology, Taiwan tahun 2017. Staf pengajar pada Jurusan Teknik Elektro FT UNP sejak tahun 2005 - sekarang. 